\title{
Analgesic efficacy of postoperative bilateral, ultrasound-guided, posterior transversus abdominis plane block for laparoscopic colorectal cancer surgery: a randomized, prospective, controlled study
}

\author{
Yang Zhao ${ }^{1}$, Han-Ying Zhang ${ }^{2}$, Zong-Yi Yuan ${ }^{3}$, Yi Han ${ }^{1}$, Yi-Rong Chen ${ }^{4}$, Qi-lin Liu ${ }^{1}$ and Tao Zhu ${ }^{5^{*}}$
}

\begin{abstract}
Background: We assessed whether a postoperative bilateral, ultrasound-guided, posterior transversus abdominis plane (TAP) block could reduce $24 \mathrm{~h}$ rescue tramadol requirement compared with placebo in patients undergoing elective laparoscopic colorectal cancer surgery.

Methods: Patients scheduled to undergo elective laparoscopic surgery following the diagnosis of colorectal cancer were included in this study and randomized into Group and Group Control. The patients received a postoperative bilateral, ultrasound-guided, posterior TAP block in either $20 \mathrm{~mL}$ of $0.5 \%$ ropivacaine (Group TAP) per side or an equivalent volume of normal saline (Group Control). The primary outcome was the cumulative consumption of rescue tramadol within $24 \mathrm{~h}$ after the surgery. Secondary endpoints included (1) resting and movement numerical rating scale (NRS) pain scores at 2, 4, 6, 12, 24, 48, and $72 \mathrm{~h}$; (2) incidences of related side effects; (3) time to the first request for rescue tramadol; (4) patient satisfaction regarding postoperative analgesia; (5) time to restoration of intestinal function; (6) time to mobilization; and (7) the length of hospital stay.

(Continued on next page)
\end{abstract}

\footnotetext{
* Correspondence: 739501155@qq.com

Statements:

The work is attributed to departments of Anesthesiology, Affiliated Hospital of North Sichuan Medical College.

${ }^{5}$ Department of Anesthesiology, West China Hospital of Sichuan University, Chengdu 610041, Sichuan, P. R. China

Full list of author information is available at the end of the article
}

C C The Author(s). 2021 Open Access This article is licensed under a Creative Commons Attribution 4.0 International License, which permits use, sharing, adaptation, distribution and reproduction in any medium or format, as long as you give appropriate credit to the original author(s) and the source, provide a link to the Creative Commons licence, and indicate if changes were made. The images or other third party material in this article are included in the article's Creative Commons licence, unless indicated otherwise in a credit line to the material. If material is not included in the article's Creative Commons licence and your intended use is not permitted by statutory regulation or exceeds the permitted use, you will need to obtain permission directly from the copyright holder. To view a copy of this licence, visit http://creativecommons.org/licenses/by/4.0/. The Creative Commons Public Domain Dedication waiver (http://creativecommons.org/publicdomain/zero/1.0/) applies to the data made available in this article, unless otherwise stated in a credit line to the data. 
(Continued from previous page)

Results: In total, 92 patients were randomized, and 82 patients completed the analysis. The total rescue tramadol requirement (median [interquartile range]) within the first $24 \mathrm{~h}$ was lower in Group TAP $(0[0,87.5] \mathrm{mg})$ than in Group Control $(100[100,200] \mathrm{mg}), P<0.001$. The posterior TAP block reduced resting and movement NRS pain scores at $2,4,6,12$, and $24 \mathrm{~h}$ after surgery (all $P<0.001$ ) but showed similar scores at $48 \mathrm{~h}$ or $72 \mathrm{~h}$. A higher level of satisfaction with postoperative analgesia was observed in Group TAP on day $1(P=0.002)$, which was similar on days $2(P=0.702)$ and $3(P=0.551)$, compared with the Group Control. A few incidences of opioid-related side effects $(P<0.001)$ and a lower percentage of patients requiring rescue tramadol analgesia within $24 \mathrm{~h}(P<0.001)$ were observed in Group TAP. The time to the first request for rescue analgesia was prolonged, and the time to mobilization and flatus was reduced with a shorter hospital stay in Group TAP as compared with Group Control.

Conclusions: A postoperative bilateral, ultrasound-guided, posterior TAP block resulted in better pain management and a faster recovery in patients undergoing laparoscopic colorectal cancer surgery, without adverse effects.

Trial registration: The study was registered at http://www.chictr.org.cn (ChiCTR-IPR-17012650; Sep 12, 2017).

Keywords: TAP block, Colorectal cancer surgery, Analgesia technique, Ropivacaine

\section{Background}

Perioperative analgesia is essential for patients undergoing elective colorectal surgery in the enhanced recovery after surgery (ERAS) program. However, postoperative pain associated with colorectal surgery is considered neuropathic and requires a multimodal treatment approach to achieve effective pain control with fewer side effects $[1,2]$. Transversus abdominis plane (TAP) block was suggested as a necessary part of the analgesia approach to control postoperative pain in several abdominal and gynecological surgical procedures [3]. The TAP technique includes injecting local anesthetics into a plane between the internal oblique (IO) and transversus abdominis (TA) muscles, which contain the thoracolumbar nerves originating from T6 to L1 spinal roots that supply the skin, muscles, parietal peritoneum, and sensation to the anterolateral abdominal wall [4, 5]. Performing an ultrasound-guided block enhanced the accuracy and efficacy of injecting local anesthetics into the TAP $[6,7]$.

The three primary approaches to TAP are subcostal, lateral, and posterior. The subcostal approach provides analgesia to the upper abdomen, whereas lateral and posterior approaches reduce the pain in the lower abdomen. Previous studies indicated that lateral TAP reduced the resting pain score within the first $6 \mathrm{~h}$ of laparoscopic colorectal surgery [8]. In contrast, posterior TAP provided 12 to $36 \mathrm{~h}$ of postoperative analgesia for total abdominal hysterectomy or cesarean delivery surgery [9, 10]. However, there is limited evidence suggesting that compared with systemic opioids or placebo, posterior TAP could reduce opioid consumption and pain scores after laparoscopic colorectal cancer surgery [2]. This study hypothesized that a postoperative bilateral, ultrasound-guided, posterior TAP could reduce the requirement for rescue analgesics within the first $24 \mathrm{~h}$ compared with placebo in patients undergoing laparoscopic colorectal cancer surgery.

\section{Methods}

\section{Patients}

This randomized, double-blinded, prospective clinical trial was registered with the Chinese registry of clinical trials at http://www.chictr.org.cn (ChiCTR-IPR17012650; Sep 12, 2017). The Research Ethics Committee of the Affiliated Hospital of North Sichuan Medical College approved the study (approval no. 2017/049). This study adhered to the applicable CONSORT guidelines and was conducted from January 2018 to December 2019 in the Affiliated Hospital of North Sichuan Medical College. Informed written consent was obtained from all participants. Inclusion criteria were patients aged 18 to 65 years without previous abdominal surgery; American Society of Anesthesiologists classification (ASA) I-III; ability to express pain; and patients who were undergoing elective laparoscopic colorectal cancer surgery. Exclusion criteria were patients who had undergone any surgery again after the elective laparoscopic colorectal cancer surgery until discharged; a history of an allergic reaction to local anesthetics or opioids; weighing less than $45 \mathrm{~kg}$ (to reduce the risk of anesthetic toxicity); a history of recent exposure to opioids; body mass index $(\mathrm{BMI}) \geq 30 \mathrm{~kg} / \mathrm{m}^{2}$; exposure to pain medication $24 \mathrm{~h}$ before the surgery; inability to use patientcontrolled intravenous analgesia; and patients undergoing resections requiring perineal incisions.

\section{Randomization and blinding}

On the day of surgery, consented patients were randomly assigned to Group TAP or Group Control (1:1) using SPSS 25.0 software (Statistical Program for Social Sciences, SPSS Inc., Chicago, Illinois, USA) by Q.-L.L., who was not involved in other parts of the study.

The anonymity of allocation was ensured by enclosing assignments in sealed, opaque, and sequentially numbered envelopes opened by a nurse (Y.H.) only upon 
patient's arrival in the operation room. The nurse prepared $0.5 \%$ ropivacaine or saline $(40 \mathrm{~mL})$ for all patients during the study period according to the allocation and did not participate in any other related process. The allocation was blinded for all patients, surgeons, anesthesiologists, and follow-up observers until the end of the study.

\section{Intervention}

Before extubation, all patients received ultrasoundguided bilateral posterior TAP block by an experienced anesthesiologist at the end of the surgery. The patient was kept in a semi-lateral position and received the posterior TAP block. An ultrasound probe was placed posterior to the mid-axillary line between the costal margin and the iliac crest [11] (Fig. 1). When scanning posteriorly, transversus abdominis tailed off and turned into aponeurosis. Subsequently, a blunt-ended needle was injected into the TAP between the internal oblique and transversus abdominis, posterior to the mid-axillary line and near the aponeurosis. Real-time imaging allowed the anesthesiologist to observe the passage of the needle through the internal oblique and its entry into the TAP endpoint near the aponeurosis. Whether the needle was placed correctly was confirmed by injecting the saline solution into the muscle plane and assessing the spread. After the confirmation, $40 \mathrm{~mL}$ of $0.5 \%$ ropivacaine was injected $(20 \mathrm{~mL}$ per side) in Group TAP and an equivalent volume of saline in Group Control. The successful injection was defined as the appearance of a hypoechoic ellipsoid with well-defined margins on ultrasound imaging $[12,13]$.

\section{Anesthesia, surgery, and postoperative analgesia}

All patients received standard perioperative care. $\mathrm{Pa}-$ tients were routinely monitored by electrocardiography.
In addition, non-invasive arterial blood pressure, arterial oxygen saturation, and end-tidal carbon dioxide were monitored, and patients were placed in the Trendelenburg position. General anesthesia was induced and maintained using intravenous midazolam $(0.04 \mathrm{mg} / \mathrm{kg})$, propofol $(2.0-3.0 \mathrm{mg} / \mathrm{kg})$, sufentanil $(0.3 \mu \mathrm{g} / \mathrm{kg})$ in both the groups. Endotracheal intubation was performed using IV administration of rocuronium $(0.6 \mathrm{mg} / \mathrm{kg})$. Sufentanil $(10 \mu \mathrm{g})$ and rocuronium $(10 \mathrm{mg})$ were administered intravenously before the incision. Anesthesia was maintained with a combined IV-inhaled anesthesia: sevoflurane $(2-4 \%)$ with oxygen $2 \mathrm{~L} / \mathrm{min}$, rocuronium $(0.1-0.2 \mathrm{mg} / \mathrm{kg} / \mathrm{h})$ was applied to maintain muscle relaxation, and remifentanil $(0.1 \mu \mathrm{g} / \mathrm{kg} / \mathrm{min})$ was used to maintain intraoperative analgesia. Sevoflurane end-tidal concentrations were titrated to maintain the bispectral index value between 40 and 60 for all patients. An IV infusion of atropine and ephedrine was used to maintain blood pressure and heart rate at the preoperative baseline range (increase and decrease in the width did not exceed $20 \%$ of the baseline value). All patients were intravenously administered $0.15 \mu \mathrm{g} / \mathrm{kg}$ sufentanil $30 \mathrm{~min}$ before the surgery finished, following the patientcontrolled intravenous anesthesia (PCIA) which was set locked until the patient becomes awake. The PCIA contained $100 \mu \mathrm{g}$ of sufentanil and $98 \mathrm{~mL}$ of saline. The PCIA was set as follows: background infusion of $2 \mu \mathrm{g} / \mathrm{h}$ sufentanil, a bolus dose of $2 \mu \mathrm{g}$ sufentanil, and a lockout interval of $5 \mathrm{~min}$ [14].

The postoperative intravenous antiemetic regimen consisted of dexamethasone $(5 \mathrm{mg})$ administered at induction and ondansetron $(4 \mathrm{mg})$ administered after the surgery. After the surgery, anesthesiologists performed ultrasound-guided bilateral posterior TAP block in all patients. After patients awoke, the tube was extubated, and they were transferred to the post-anesthesia care
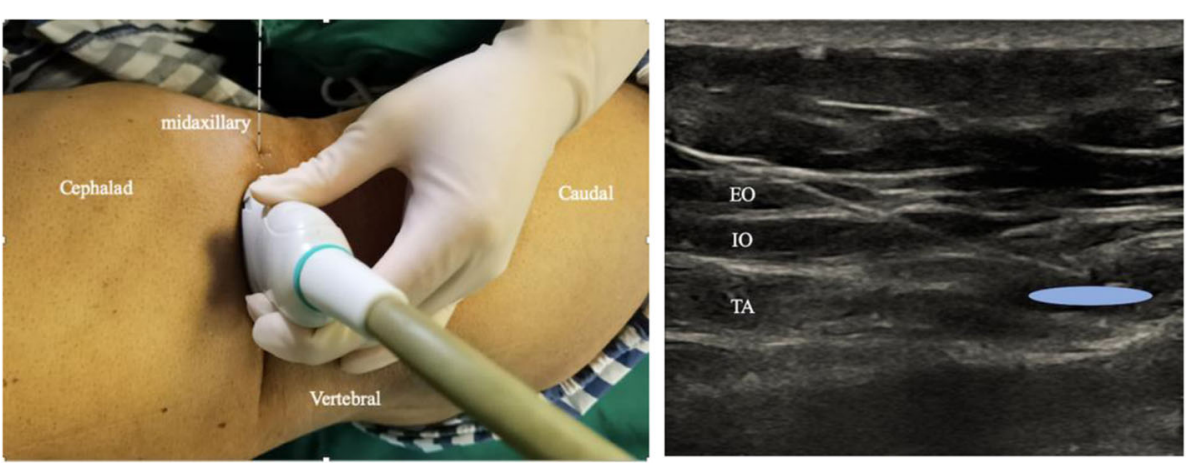

Fig. 1 Posterior approach of transversus abdominis plane (TAP) block. Note: a The patient was kept in semi-lateral position, the probe position and needle trajectory were displayed. The probe is placed posterior to the midaxillary line between the costal margin and the iliac crest. The needle is inserted in plane. $\mathbf{b}$ Corresponding ultrasound images. Posterior approach located in the end of transversus abdominis plane where TAP transmigrate into aponeurosis. The injection site is at the TAP between internal oblique and transversus abdominis posterior to the midaxillary line and near the aponeurosis. White dashed line: needle trajectory. Light blue area: the deposition site of local anesthetic. TA: transversus abdominis; IO: internal oblique; EO: external oblique 
unit (PACU) for further monitoring. If the patient complained of an 11-point numerical rating scale for pain (NRS, $0=$ no pain; $10=$ worst pain imaginable) exceeded 3 , a muscular injection of rescue tramadol $(50 \mathrm{mg})$ was offered, which was allowed to repeat at a maximum dose of $400 \mathrm{mg}$ per day [15]. In addition, rescue antiemetics were provided to patients complaining of nausea or vomiting. Early mobilization was encouraged since the patient was transferred to the ward. Patients met the discharge criteria if they could have a soft diet, were completely mobilized, and had an NRS score lower than 3 .

\section{Follow-up and outcomes}

Patients were evaluated from PACU until discharge from the hospital by the same investigator who was blinded to randomization. The primary outcome was the cumulative consumption of rescue tramadol within $24 \mathrm{~h}$ after the surgery. Secondary endpoints included (1) resting and movement NRS scores assessed at 2, 4, 6, 12, 24, 48, and $72 \mathrm{~h}$, postoperatively [16-18]; (2) incidences of related side effects, such as nausea, vomiting, pruritus, sedation, and respiratory depression; (3) time to the first requirement of rescue tramadol muscular injection; (4) patient satisfaction on postoperative analgesia at 24,48 , and $72 \mathrm{~h}$ after the surgery using a 5-point scale [19] $(1=$ very unsatisfied, 2 = unsatisfied, $3=$ fair, $4=$ satisfied, and $5=$ very satisfied); (5) time for restoration of intestinal function; (6) time to the first mobilization; and (7) length of hospital stay (number of nights spent in the hospital from the date of surgery to discharge).

\section{Sample size}

The sample size was based on the $24 \mathrm{~h}$ rescue tramadol requirement of patients undergoing laparoscopic colorectal cancer surgery. To calculate the sample size, a clinically significant reduction in $24 \mathrm{~h}$ tramadol consumption was considered as a $20 \%$ absolute reduction with a conservative assumption. Based on initial pilot studies, we found that $24 \mathrm{~h}$ tramadol requirement was $110 \pm 34.2 \mathrm{mg}$ in the control group of 10 subjects. With a statistical power of 0.8 and a type 1 error rate of 0.05 to detect $20 \%$ improvement as conservative, the minimum requirement to demonstrate a difference using a two-tailed Student's $t$-test was a sample size of 38 patients per group. Considering a possible dropout rate of $20 \%$, we included 92 patients in this study.

\section{Statistical analysis}

The collected data were analyzed using SPSS 25.0 software (Statistical Program for Social Sciences, SPSS Inc., Chicago, Illinois, USA), with a two-tailed $P$-value $<0.05$ considered statistically significant. Continuous variables were presented as means \pm standard deviations or medians \pm interquartile range (IQR), or absolute numbers.
The log-rank test was to compare the time to the first request of rescue tramadol. Categorical variables are presented as percentages. The two-sample Student's $t$-test or the Mann-Whitney U-test was used for continuous variables, and the Chi-squared test compared differences in the qualitative data.

\section{Results}

One hundred twenty-six consecutive patients were assessed for eligibility between January 2018 and December 2019. Of these, 28 patients did not meet the inclusion criteria, and 6 patients refused to participate. The remaining 92 patients were randomized into Group TAP $(n=46)$ and Group Control $(n=46)$ to receive TAP intervention and a sham block, respectively. Laparoscopic surgeries were converted to open surgery in six patients of Group TAP and four patients in the Group Control. These ten patients were excluded from the outcome analysis. Eighty-two patients successfully underwent a postoperative bilateral, ultrasound-guided, posterior TAP block, which was determined by the bilateral appearance of a hypoechoic ellipsoid ultrasound image $[12,13]$. Because no patient was lost to follow-up, 40 patients from Group TAP and 42 from Group Control were analyzed (Fig. 2). Both groups were similar in terms of sex, age, BMI, ASA, surgery duration, comorbidities, intraoperative analgesics, and extraction incision used (Table 1).

The (median [interquartile range]) cumulative consumption of rescue tramadol within $24 \mathrm{~h}$ was significantly lower in Group TAP $(0 \mathrm{mg}[0,87.5])$, compared with Group Control (100 mg [100, 200]), $P<0.001$ (Table 2).

A longer time to first tramadol muscular injection request was observed in Group TAP than the Group Control (Fig. 3). The (median [interquartile range]) time to first request for tramadol was significantly more in Group TAP (1440 min [285, 1440]) compared with Group Control (50 min [30, 90]; $P<0.001$ ) (Table 2).

Resting NRS scores were lower in Group TAP than in Group Control at $2(1.3 \pm 0.5$ vs. $3.4 \pm 1.1), 4(1.5 \pm 0.5$ vs. $2.2 \pm 0.4), 6(1.7 \pm 0.6$ vs. $2.7 \pm 0.6), 12(1.7 \pm 0.7$ vs. $2.3 \pm 0.6)$, and $24 \mathrm{~h}(1.7 \pm 0.6$ vs. $2.1 \pm 0.4)$ after the surgery (all $\mathrm{P}<0.001)$ but similar at $48(2.1 \pm 0.6$ vs. $2.1 \pm$ $0.5, P=0.862)$ or $72 \mathrm{~h}(2.0 \pm 0.7$ vs. $2.1 \pm 0.7, P=0.648)$. In addition, movement NRS scores were lower in Group TAP than in Group Control at $2(2.1 \pm 0.4$ vs. $4.1 \pm 1.2)$, 4 ( $2.2 \pm 0.5$ vs. $3.1 \pm 0.5), 6$ ( $2.3 \pm 0.6$ vs. $3.5 \pm 0.7), 12$ $(2.3 \pm 0.5$ vs. $2.9 \pm 0.3)$, and $24 \mathrm{~h}(2.2 \pm 0.4$ vs. $2.7 \pm 0.5)$ after the surgery (all $P<0.001)$ but similar at $48 \mathrm{~h}(3.1 \pm$ 0.6 vs. $3.2 \pm 0.7, P=0.760)$ or 72 h $(3.0 \pm 0.5$ vs. $3.0 \pm 0.6$, $P=0.992)$ (Figs. 4 and 5).

The incidence of nausea and vomiting was lower in Group TAP than in Group Control. No pruritus, 


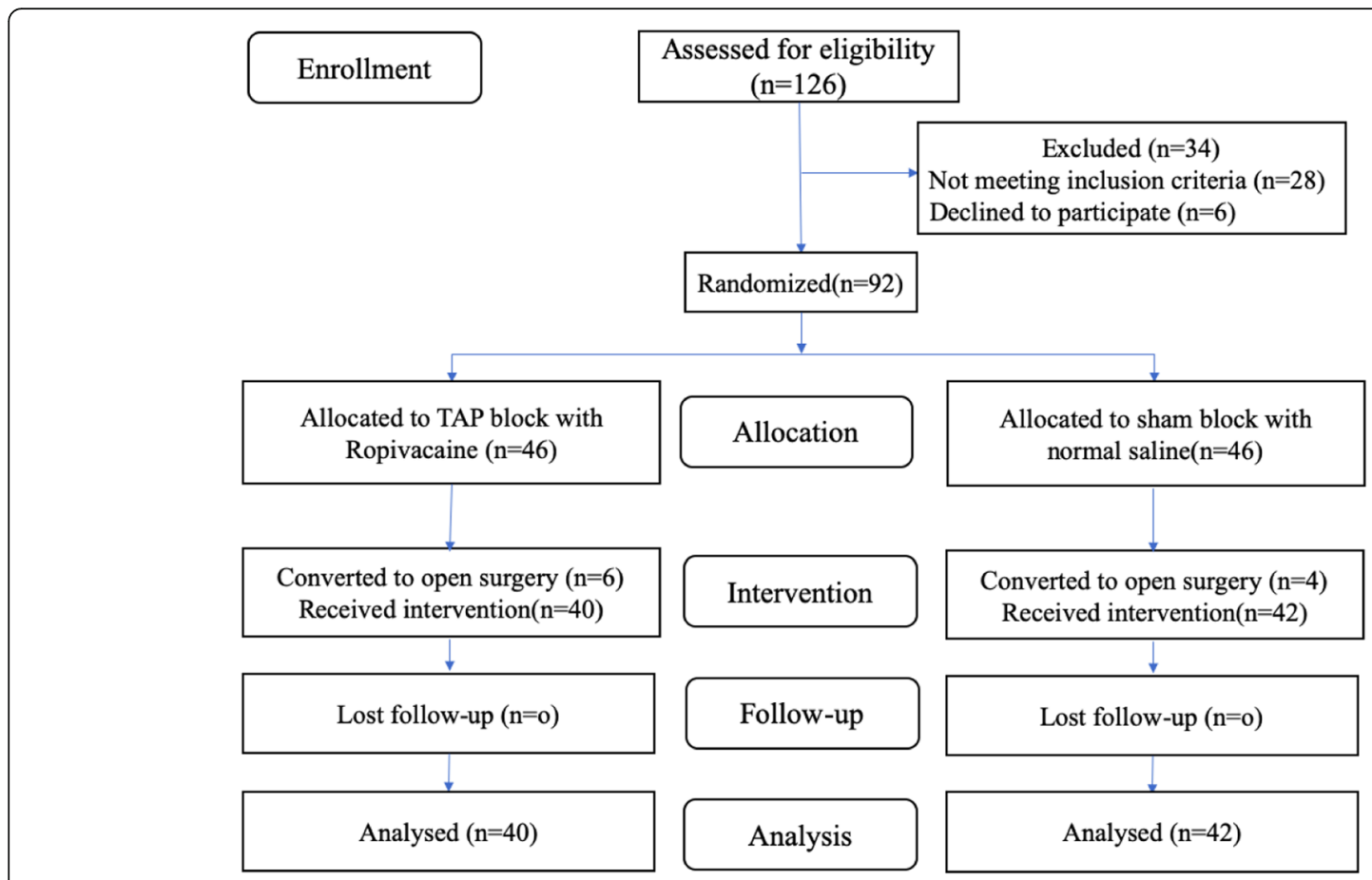

Fig. 2 Consort flow study diagram. Note: TAP: transversus abdominis plane

sedation, and respiratory depression occurred in both groups (Table 3 ).

Table 4 shows patients' postoperative satisfaction level on analgesia. Patients' satisfaction was significantly higher in Group TAP on postoperative day $1(P=0.012)$ but similar on days 2 and 3, compared with Group Control.

The first time to get out of bed was significantly earlier in Group TAP than in Group Control $(27.9 \pm 7.8$ vs. $33.9 \pm 8.2 \mathrm{~h}, P=0.001)$. Time to first passage of flatus was significantly earlier in Group TAP than in Group Control $(32.4 \pm 6.2$ vs. $39.0 \pm 8.7 \mathrm{~h}, P<0.001)$ (Table 2). The mean length of hospital stay was significantly shorter in Group TAP than in Group Control $(3.4 \pm 0.5$ vs. $3.9 \pm 0.6$ days, $\mathrm{P}<0.001$ ) (Table 2 ).

\section{Discussion}

In this study, a postoperative bilateral, ultrasoundguided, posterior TAP using $0.5 \%$ ropivacaine $(20 \mathrm{~mL}$ per side) reduced and delayed the requirement for

Table 1 Demographic and intraoperative characteristics

\begin{tabular}{|c|c|c|c|}
\hline variables & Group TAP $(n=40)$ & Group Control $(n=42)$ & $P$ value \\
\hline Mean age, year & $51.4 \pm 7.4$ & $52.1 \pm 8.4$ & \\
\hline Gender, male: female & $18: 22$ & $22: 20$ & \\
\hline $\mathrm{BMI}(\mathrm{kg} / \mathrm{m} 2)$ & $23.6 \pm 2.7$ & $23.8 \pm 2.6$ & \\
\hline ASA I / II / II & $8 / 28 / 4$ & $7 / 33 / 2$ & 0.903 \\
\hline Operation time (min) & $162.7 \pm 33.4$ & $164.3 \pm 30.4$ & 0.820 \\
\hline Type of operation & & & 0.995 \\
\hline Right hemicolectomy & $16(40)$ & $16(38)$ & / \\
\hline Left hemicolectomy & $12(30)$ & $13(31)$ & / \\
\hline Anterior resection & $6(15)$ & $7(17)$ & / \\
\hline Sigmoid colectomy & $6(15)$ & $6(14)$ & / \\
\hline Intraoperative sufentanil usage (ug) & $37.7 \pm 4.2$ & $37.6 \pm 4.3$ & 0.941 \\
\hline Intraoperative remifentanil usage (mg) & $1.0 \pm 0.3$ & $1.0 \pm 0.3$ & 0.979 \\
\hline
\end{tabular}


Table 2 Comparison of clinical outcomes between the groups

\begin{tabular}{|c|c|c|c|}
\hline & Group TAP $(n=40)$ & Group Control $(n=42)$ & $P$ value \\
\hline Tramadol consumption within $24 \mathrm{~h}$ after surgery $(\mathrm{mg})^{a}$ & $0(0,87.5)$ & $100(100,200)$ & $<0.001$ \\
\hline Time to first requirement of rescue tramadol muscular injection (min) ${ }^{a}$ & $1440(285,1440.00)$ & $50(30,90)$ & $<0.001$ \\
\hline time to flatus (h) & $32.4 \pm 6.2$ & $39.0 \pm 8.7$ & $<0.001$ \\
\hline time to mobilization (h) & $27.9 \pm 7.8$ & $33.9 \pm 8.2$ & 0.001 \\
\hline length of hospital stay $(\mathrm{d})$ & $3.4 \pm 0.5$ & $4.0 \pm 0.6$ & $<0.001$ \\
\hline
\end{tabular}

Note: Data are presented as mean \pm SD, unless otherwise indicated. ${ }^{\mathrm{a}}$ Data are presented as median and quartiles, and analyzed by Mann-Whitney $\mathrm{U}$ test. Group TAP = transversus abdominis plane block

rescue analgesics within the first $24 \mathrm{~h}$. Besides, the resting and movement pain scores also decreased at 2, 4, 6 , 12 , and $24 \mathrm{~h}$ in Group TAP. Less related side effects, accelerated bowel function recovery, and shorter hospital stay were observed in Group TAP compared with Group Control.

Excessive perioperative opioid consumption increases the incidence of postoperative nausea and vomiting (PONV), sedation, pruritus, urinary retention, bowel dysfunction, and respiratory depression, and delays postoperative recovery [20-22]. The resting and movement NRS scores in Group TAP were lower than those in Group Control at 2, 4, 6, 12, and 24h after the surgery. Although the pain scores in Group TAP differentiate from Group Control slightly, early effective analgesia contributed to lower and delayed rescue analgesia requirement of tramadol muscular injection in Group TAP, resulting in tramadol spare-effect. In this study, the application of posterior TAP in Group TAP significantly reduced tramadol consumption and the incidence of PONV $24 \mathrm{~h}$ after the surgery compared with the Group Control. Thus, the reduction in PONV could be explained by the decrease in tramadol-related adverse effects. Early pain relief and fewer side effects allowed the patients to get up and ambulate. Moreover, it was associated with earlier mobilization, better bowel function recovery, shorter hospital stay, and better satisfaction [23]. However, the pain scores in the two groups were similar at 48 or $72 \mathrm{~h}$ and were consistently very low, this could be due to the analgesic effects of PCIA and the minimal invasive advantages of laparoscopic over open surgery for all participants [24]. However, half-day reduction of hospital stay was statistically significant $(3.4 \pm 0.5$ vs. $3.9 \pm 0.6 \mathrm{~d}, P<0.001)$, the clinical significance was relatively limited.

Postoperative analgesia is an essential part of perioperative anesthetic management and the enhanced recovery program. After the surgery, acute pain

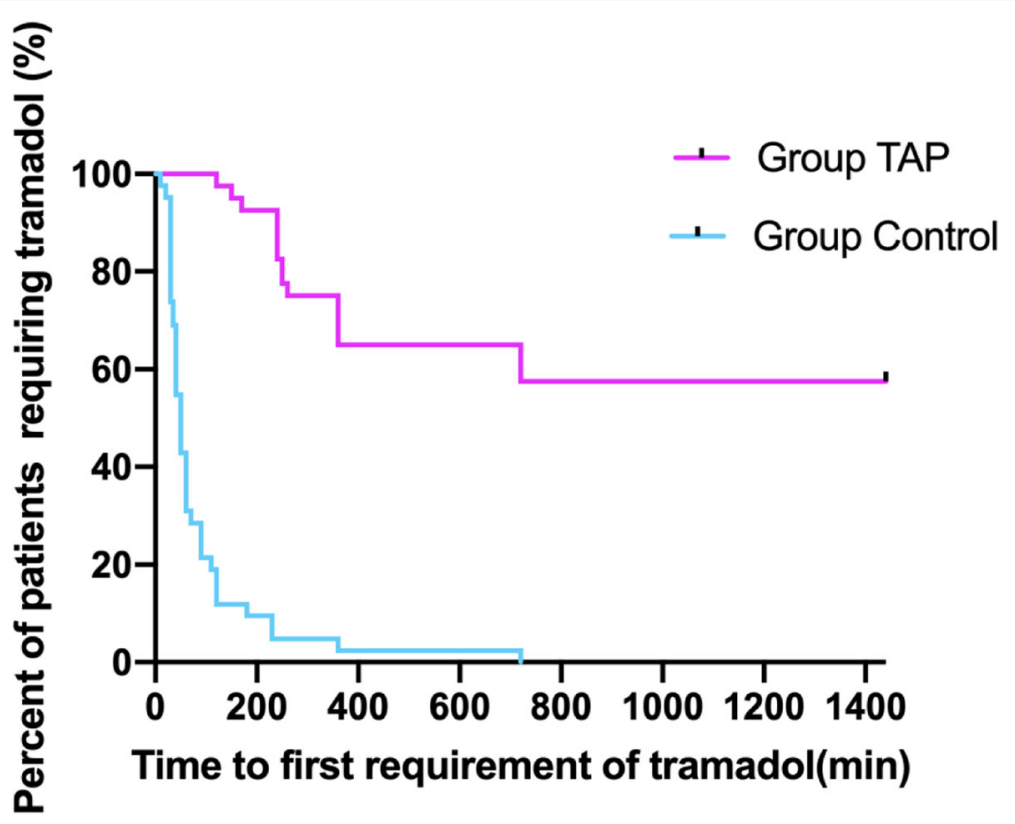

Fig. 3 Kaplan-Meier curve depicting time to first tramadol requirement during postoperative 24-h follow-up among two groups. Note: Group TAP $=$ transversus abdominis plane block, $\mathrm{P}<0.001$ 


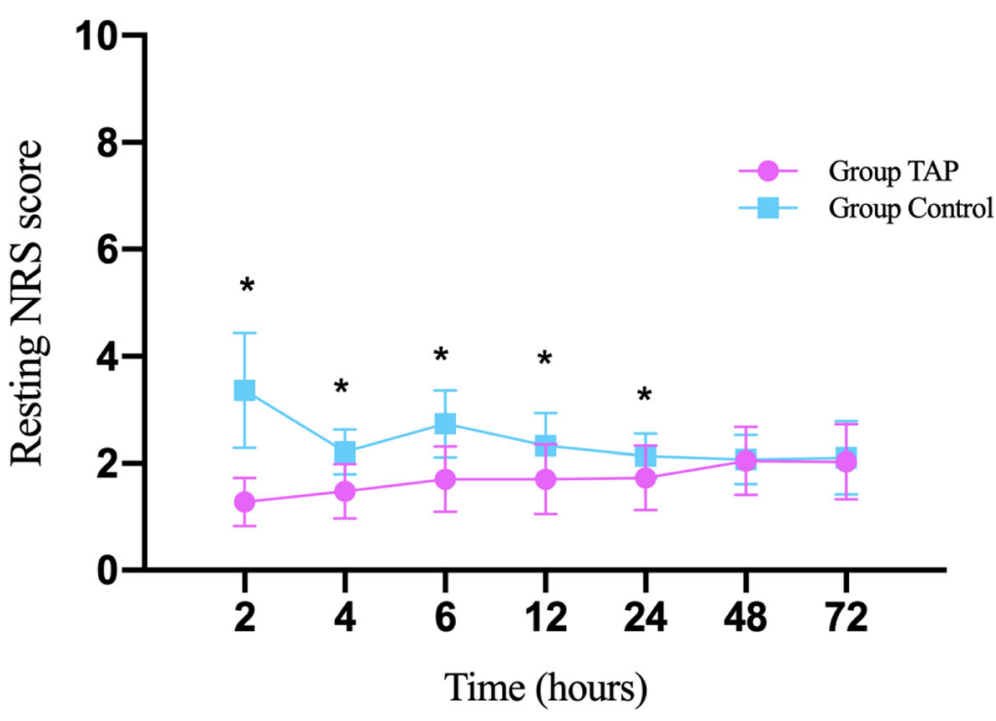

Fig. 4 Comparison of resting NRS scores at different times after surgery between the groups. Note: Mean postoperative resting NRS scores assessed by using an 11-point numerical rating scale $(0=$ no pain and $10=$ the worst imaginable pain) at different times after surgery in each group. *Indicates NRS score significantly difference $(P<0.001$, t-test) between two groups. Group TAP $=$ transversus abdominis plane block

significantly contributes to the increased hospital stay and patient dissatisfaction [25]. Pain derived from the abdominal wall incision was the primary component experienced by the patients after abdominal surgery [12]. Recently, TAP has been recommended as an essential component of multimodal analgesia techniques because it provides effective analgesia for abdominal surgical procedures, including colorectal surgery [26, 27]. It blocks the T6-L1 spinal nerves' neural branches dominating the anterolateral abdominal wall [11]. After the anterior rami of these nerves exit their respective vertebral foramina, they enter the anterior abdomen muscles and reach the neurofascial plane between the internal oblique and transversus abdominis muscles. The sensory nerve branch first sends out a lateral cutaneous branch in the mid-axillary line and continues to move within the plane to supply the anterior skin [12]. The posterior TAP is located between the costal margin and the iliac

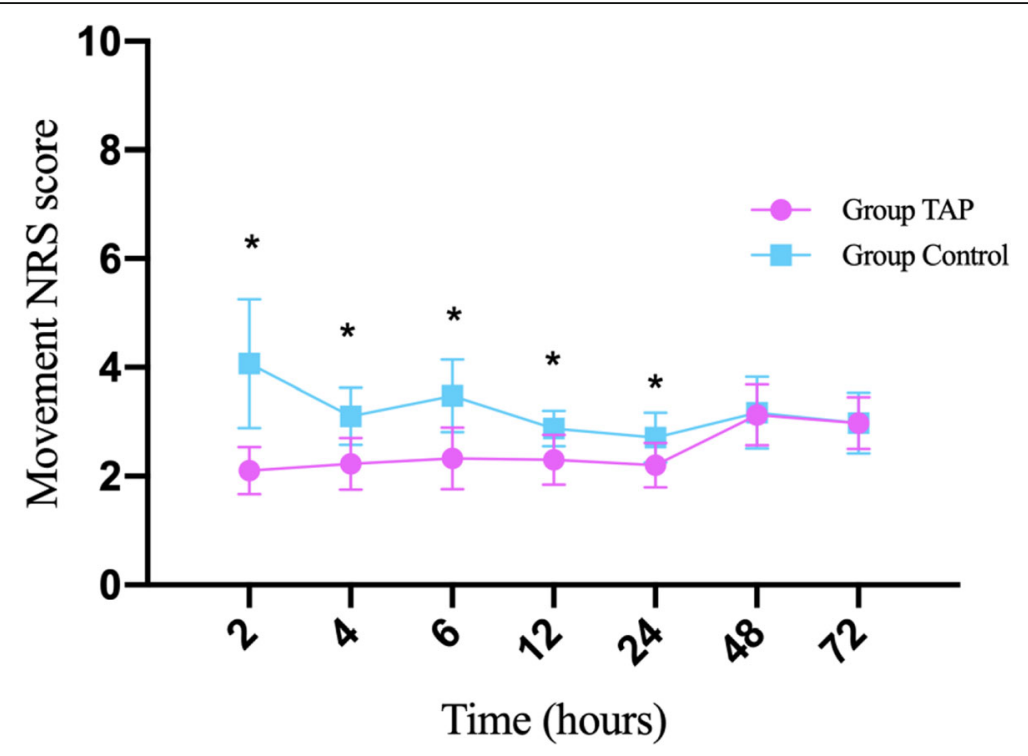

Fig. 5 Comparison of movement NRS scores at different times after surgery between the groups. Note: Mean postoperative moving NRS scores assessed by using an 11-point numerical rating scale $(0=$ no pain and $10=$ the worst imaginable pain) at different times after surgery in each group. * Indicates NRS score significantly difference $(P<0.001$, t-test) between two groups. Group TAP = transversus abdominis plane block 
Table 3 Comparison of postoperative side effects between the groups

\begin{tabular}{llll}
\hline Side effects & Group TAP $(\mathbf{n}=\mathbf{4 0})$ & Group Control $(\mathbf{n}=\mathbf{4 2})$ & $<$ \\
\hline Nausea & $11 / 40$ & $32 / 42$ & $<0.001$ \\
Vomiting & $3 / 40$ & $17 / 42$ & $<0.001$ \\
Pruritus & $0 / 40$ & $0 / 42$ & $/$ \\
Sedation & $0 / 40$ & $0 / 42$ & $/$ \\
Respiratory depression & $0 / 40$ & $0 / 42$ & $/$ \\
\hline
\end{tabular}

Note: Data are presented as the number of case. Group TAP = transversus abdominis plane block

crest. In the present study, the needle was inserted at the mid-axillary line. A large volume of a local anesthetic was deposited in the transverse abdominal plane by the mid-axillary line puncture that blocked the lateral cutaneous branches, thereby completely blocking the anterior abdominal wall [12]. Similar research on cadavers and volunteers demonstrated that posterior TAP provided analgesia effect from the anterior-lateral abdominal area to the post-axillary line $[28,29]$. In addition, different approaches of TAP substantially influenced the spread pattern of local anesthetics within the plane. It has been reported that local anesthetics mostly spread into the layer between the internal oblique and external oblique muscles in the subcostal and lateral TAP approaches without extending into the paravertebral space, resulting in somatic pain relief in the anterior abdominal wall. However, in posterior TAP, local anesthetic may partly enter the paravertebral space covering $\mathrm{T} 4$ to $\mathrm{L} 1 \mathrm{in}$ a retrograde fashion and potentially blocking a few degrees along with the thoracolumbar sympathetic system, resulting in a more comprehensive somatic pain relief in the abdominal wall [30-32]. Because the sympathetic nervous system mediates pain after the surgery, the posterior TAP could achieve a prolonged analgesic effect. Besides, the postoperative TAP may prolong the analgesic effect by delaying the metabolism process compared with preoperative TAP [33]. Finally, the posterior TAP injection probably causes deposition of the local anesthetic in the aponeurosis, which acts as "warehouse effect" that plausibly intensifies and prolongs the effect of posterior TAP [34, 35]. Taking all these into account, we considered that a single shot of posterior and postoperative TAP with $0.5 \%$ ropivacaine relieved the pain efficiently during $24 \mathrm{~h}$ follow-up although the duration of ropivacaine only lasted $4-8 \mathrm{~h}$ in pharmacokinetic, our results were similar to previous studies $[12,36]$.
A previous study indicated that a preoperative bilateral, ultrasound-guided, lateral TAP block using $2 \mathrm{mg} / \mathrm{kg}$ levobupivacaine $(40 \mathrm{~mL})$ equally split between the sides (up to a total maximum dose of $150 \mathrm{mg}$ ) decreased the pain scores only at 2, 4, and $6 \mathrm{~h}$ [33]. However, we observed that the postoperative bilateral, ultrasoundguided, posterior TAP produced $24 \mathrm{~h}$ analgesia in laparoscopic colorectal surgery, indicating that the posterior TAP prolonged postoperative analgesia. Thus, it is not surprising that the posterior TAP block in our study provided a reliable, satisfied, and durable analgesia effect for laparoscopic cancer surgery. Moreover, both preoperative and postoperative timings are suitable for performing TAP. However, we selected the postoperative TAP over preoperative TAP, owing to its advantages, such as avoiding local anesthetic distribution within the muscle layers caused by the long head-down position and delaying the local anesthetic metabolization [33].

TAP block is a superficial technique, where the target depth is usually between 1 and $3 \mathrm{~cm}$, with a small but finite risk of complications [37]. The ultrasound-guided TAP block is a relatively safe intervention without adverse outcomes [12, 38, 39]. The semi-lateral position ensures abdominal organs to be considerably away from the needle trajectory, making posterior TAP safe. Therefore, ultrasound-guided posterior TAP block is considered a safe technique for postoperative analgesia.

Our study had several limitations. First, our study did not measure the plasma concentrations of ropivacaine. Ropivacaine for TAP block could result in systemic toxicity, indicating it is essential to monitor the local anesthetic concentration. However, any symptoms of local anesthetic systemic toxicity, such as seizures, cardiovascular collapse, metallic taste, and tinnitus, did not occur in our study, whether immediately after the block

Table 4 Comparison of satisfaction on postoperative analgesia at different times between the groups

\begin{tabular}{llll}
\hline & Group TAP $(\mathbf{n}=\mathbf{4 0})$ & Group Control $(\mathbf{n}=\mathbf{4 2})$ & P value \\
\hline $24 \mathrm{~h}$ after surgery & $4(3,4)$ & $3(3,4)$ & 0.002 \\
$48 \mathrm{~h}$ after surgery & $4(4,4)$ & $4(4,4)$ & 0.702 \\
$72 \mathrm{~h}$ after surgery & $4(4,4)$ & $4(3,4)$ & 0.551 \\
\hline
\end{tabular}

Note: Data are presented as median and quartiles, and analyzed by Mann-Whitney $\mathrm{U}$ test. Assessed satisfaction using a 5-point scale $(1=$ very unsatisfied, $2=$ unsatisfied, $3=$ fair, $4=$ satisfied, and $5=$ very satisfied). Group TAP = transversus abdominis plane block 
or in the follow-up period. Second, the sensory block effect of posterior TAP was not assessed because the patient was still under general anesthesia. However, we confirmed that the needle passed through different muscle layers until its tip entered the layer between the internal oblique and transverse muscles. A hypoechoic ellipsoid with well-defined margins was indicative of successful injection under the ultrasound-guided TAP block, similar to previous studies [12, 13]. Third, although TAP block was a considerable analgesic regimen for laparoscopic colorectal cancer surgery, it was not more beneficial in patients who underwent different abdominal surgeries, especially those who received multimodal analgesia, which contained epidural analgesia, continuous lidocaine infusion, wound local infiltration, or quadratus lumborum block [40-42].

\section{Conclusions}

This prospective, randomized, double-blinded trial showed that postoperative bilateral, ultrasound-guided, posterior TAP block using $20 \mathrm{~mL}$ of $0.5 \%$ ropivacaine per side decreased the cumulative consumption of rescue tramadol within $24 \mathrm{~h}$ after the surgery. The pain scores also decreased significantly at rest and movement at $2,4,6,12$, and $24 \mathrm{~h}$ for patients undergoing laparoscopic colorectal cancer surgery. A delayed and lower requirement of tramadol muscular injection accelerated the bowel function recovery, and shorter hospital stay was observed compared with placebo without an increase in adverse events.

\section{Abbreviations \\ TAP: Transversus abdominis plane; IV: Intravenous; NRS: Numerical rating scale; ERAS: Enhanced recovery after surgery; IO: Internal oblique; TA: Transversus abdominis; ASA: American Society of Anesthesiologists classification; BMI: Body mass index; PCIA: Patient-controlled intravenous anesthesia; PACU: Post-anesthesia care unit; IQR: Interquartile range; PONV: Postoperative nausea and vomiting}

\section{Acknowledgments}

Not applicable.

\section{Authors' contributions}

T.-Z. and Y. $Z$ are responsible for the idea and design of the study. Y.Z. performed the TAP technique and drafted the manuscript. H.-Y.Z. and Y.-R.C collected and analyzed the data. L.-Q.L randomized and controlled the research quality. Y.-H. prepared ropivacaine or saline solution for TAP. Z.-Y. Y analyzed the data and prepared the tables and figures. T.-Z. revised the manuscript. All authors read and approved the final manuscript.

\section{Authors' information \\ Tao Zhu: Professor, Ph.D., Doctoral Supervisor, Vice Chief of the Department of Anesthesiology, West China Hospital of Sichuan University, Chengdu, 610041, Sichuan, P.R. China. Major in anesthesiology, perioperative organ protection, mechanism of anesthetic drugs, and perioperative information management. Published over $30 \mathrm{SCl}$ papers as first author or corresponding author.}

\section{Funding}

This research was funded by the project of Affiliated Hospital North Sichuan Medical College (grant no. (2016)163, belongs to Yang Zhao). The funding supported the publishing cost of the study.

\section{Availability of data and materials}

Data have been uploaded successfully to the Chinese registry of clinical trials at http://www.chictr.org.cn. The datasets used and/or analyzed during the current study are available from the corresponding author upon reasonable request.

\section{Declarations}

\section{Ethics approval and consent to participate}

This randomized, double-blinded, prospective clinical trial study was registered with the Chinese registry of clinical trials at http://www.chictr.org.cn (ChiCTR-IPR-17012650; Sep 12, 2017). The Research Ethics Committee of the Affiliated Hospital of North Sichuan Medical College approved the study (approval no. 2017/049). This study adhered to the applicable CONSORT guidelines and was performed from January 2018 to December 2019. The first participant enrolled on January 4, 2018. Informed written consent was obtained from all participants.

\section{Consent for publication}

Not applicable.

\section{Competing interests}

The authors declare no competing interests.

\section{Author details}

'Department of Anesthesiology, Affiliated Hospital of North Sichuan Medical College, Nanchong, Sichuan, China. ${ }^{2}$ Department of Anesthesiology, Pidu District People's Hospital, 156\# East Street, Pitong Town, Pidu District, Chengdu, Sichuan 611730, People's Republic of China. ${ }^{3}$ Departments of Oral and Maxillofacial, Nanchong Central Hospital, The Second Clinical Medical College, North Sichuan Medical College (University), Nanchong, Sichuan, China. ${ }^{4}$ Department of Anesthesiology, Affiliated Hospital of Southwest Medical University, Luzhou, Sichuan, China. ${ }^{5}$ Department of Anesthesiology, West China Hospital of Sichuan University, Chengdu 610041, Sichuan, P. R. China.

Received: 8 December 2020 Accepted: 23 March 2021

Published online: 06 April 2021

\section{References}

1. Karthikesalingam A, Walsh SR, Markar SR, Sadat U, Tang TY, Malata CM. Continuous wound infusion of local anaesthetic agents following colorectal surgery: systematic review and meta-analysis. World I Gastroenterol. 2008; 14(34):5301-5. https://doi.org/10.3748/wjg.14.5301.

2. Nygren J, Thacker J, Carli F, Fearon KC, Norderval S, Lobo DN, et al. Guidelines for perioperative care in elective rectal/pelvic surgery: enhanced recovery after surgery (ERAS((R))) society recommendations. World I Surg. 2013;37(2):285-305. https://doi.org/10.1007/s00268-012-1787-6.

3. Bonnet F, Berger J, Aveline C. Transversus abdominis plane block: what is its role in postoperative analgesia? Br J Anaesth. 2009;103(4):468-70. https:// doi.org/10.1093/bja/aep243.

4. Rozen WM, Tran TM, Ashton MW, Barrington MJ, Ivanusic JJ, Taylor Gl. Refining the course of the thoracolumbar nerves: a new understanding of the innervation of the anterior abdominal wall. Clin Anat. 2008;21(4):325-33. https://doi.org/10.1002/ca.20621.

5. Karaman T, Ozsoy AZ, Karaman S, Dogru S, Tapar H, Sahin A, et al. The effects of transversus abdominis plane block on analgesic and anesthetic consumption during total abdominal hysterectomy: a randomized controlled study. Rev Bras Anestesiol. 2018;68(3):285-91. https://doi.org/10.1 016/j.bjan.2017.12.005

6. Walter EJ, Smith P, Albertyn R, Uncles DR. Ultrasound imaging for transversus abdominis blocks. Anaesthesia. 2008;63(2):211. https://doi.org/1 0.1111/j.1365-2044.2007.05424.X.

7. Joshi GP, Bonnet F, Kehlet $H$, collaboration P. Evidence-based postoperative pain management after laparoscopic colorectal surgery. Color Dis. 2013; 15(2):146-55. https://doi.org/10.1111/j.1463-1318.2012.03062.x.

8. Abdallah FW, Laffey JG, Halpern SH, Brull R. Duration of analgesic effectiveness after the posterior and lateral transversus abdominis plane block techniques for transverse lower abdominal incisions: a meta-analysis. Br J Anaesth. 2013;111(5):721-35. https://doi.org/10.1093/bja/aet214. 
9. McDonnell JG, Curley G, Carney J, Benton A, Costello J, Maharaj CH, et al. The analgesic efficacy of transversus abdominis plane block after cesarean delivery: a randomized controlled trial. Anesth Analg. 2008;106(1):186-91 table of contents.

10. Carney J, McDonnell JG, Ochana A, Bhinder R, Laffey JG. The transversus abdominis plane block provides effective postoperative analgesia in patients undergoing total abdominal hysterectomy. Anesth Analg. 2008; 107(6):2056-60. https://doi.org/10.1213/ane.0b013e3181871313.

11. Tsai HC, Yoshida T, Chuang TY, Yang SF, Chang CC, Yao HY, et al. Transversus Abdominis plane block: an updated review of anatomy and techniques. Biomed Res Int. 2017:2017:8284363.

12. McDonnell JG, O'Donnell B, Curley G, Heffernan A, Power C, Laffey JG. The analgesic efficacy of transversus abdominis plane block after abdominal surgery: a prospective randomized controlled trial. Anesth Analg. 2007; 104(1):193-7. https://doi.org/10.1213/01.ane.0000250223.49963.0f.

13. Li X, Xu ZZ, Li XY, Jiang TT, Lin ZM, Wang DX. The analgesic efficacy of ultrasound-guided transversus abdominis plane block for retroperitoneoscopic renal surgery: a randomized controlled study. BMC Anesthesiol. 2019;19(1):186. https://doi.org/10.1186/s12871-019-0850-3.

14. Gao Y, Deng X, Yuan H, Leng Y, Zhang T, Xu X, et al. Patient-controlled intravenous analgesia with combination of Dexmedetomidine and Sufentanil on patients after abdominal operation: a prospective, randomized, controlled, blinded, Multicenter Clinical Study. Clin J Pain. 2018; 34(2):155-61. https://doi.org/10.1097/AJP.0000000000000527.

15. Dewinter G, Coppens S, Van de Velde M, D'Hoore A, Wolthuis A, Cuypers E, et al. Quadratus Lumborum block versus perioperative intravenous Lidocaine for postoperative pain control in patients undergoing laparoscopic colorectal surgery: a prospective, randomized, Double-blind Controlled Clinical Trial. Ann Surg. 2018;268(5):769-75. https://doi.org/10.1097/SLA.0000000000002888.

16. Petersen $\mathrm{PL}$, Hilsted KL, Dahl JB, Mathiesen O. Bilateral transversus abdominis plane (TAP) block with 24 hours ropivacaine infusion via TAP catheters: a randomized trial in healthy volunteers. BMC Anesthesiol. 2013; 13(1):30. https://doi.org/10.1186/1471-2253-13-30.

17. Faiz SHR, Alebouyeh MR, Derakhshan P, Imani F, Rahimzadeh $P$, Ghaderi Ashtiani M. Comparison of ultrasound-guided posterior transversus abdominis plane block and lateral transversus abdominis plane block for postoperative pain management in patients undergoing cesarean section: a randomized double-blind clinical trial study. J Pain Res. 2018;11:5-9. https:// doi.org/10.2147/JPR.S146970.

18. Smith SR, Draganic B, Pockney P, Holz P, Holmes R, McManus B, et al. Transversus abdominis plane blockade in laparoscopic colorectal surgery: a double-blind randomized clinical trial. Int J Color Dis. 2015;30(9):1237-45. https://doi.org/10.1007/s00384-015-2286-7.

19. Tawfik MM, Mohamed YM, Elbadrawi RE, Abdelkhalek M, Mogahed MM, Ezz HM. Transversus Abdominis plane block versus wound infiltration for analgesia after cesarean delivery: a randomized controlled trial. Anesth Analg. 2017;124(4):1291-7. https://doi.org/10.1213/ANE.0000000000001724.

20. White PF, Kehlet H, Neal JM, Schricker T, Carr DB, Carli F, et al. The role of the anesthesiologist in fast-track surgery: from multimodal analgesia to perioperative medical care. Anesth Analg. 2007;104(6):1380-96 table of contents.

21. Shirakami G, Teratani $Y$, Segawa H, Matsuura S, Shichino T, Fukuda K. Omission of fentanyl during sevoflurane anesthesia decreases the incidences of postoperative nausea and vomiting and accelerates postanesthesia recovery in major breast cancer surgery. J Anesth. 2006;20(3): 188-95. https://doi.org/10.1007/s00540-006-0413-x.

22. Walder B, Schafer M, Henzi I, Tramer MR. Efficacy and safety of patientcontrolled opioid analgesia for acute postoperative pain. A quantitative systematic review. Acta Anaesthesiol Scand. 2001;45(7):795-804. https://doi. org/10.1034/j.1399-6576.2001.045007795.x.

23. Keller DS, Ermlich BO, Schiltz N, Champagne BJ, Reynolds HL Jr, Stein SL, et al. The effect of transversus abdominis plane blocks on postoperative pain in laparoscopic colorectal surgery: a prospective, randomized, double-blind trial. Dis Colon Rectum. 2014;57(11):1290-7. https://doi.org/10.1097/DCR.0000000000000211.

24. Kikuchi S, Kuroda S, Nishizaki M, Matsusaki T, Kuwada K, Kimura Y, et al. Comparison of the effects of epidural analgesia and patient-controlled intravenous analgesia on postoperative pain relief and recovery after laparoscopic Gastrectomy for gastric Cancer. Surg Laparosc Endosc Percutan Tech. 2019;29(5):405-8. https://doi.org/10.1097/SLE.0000000000000605.

25. Mhuircheartaigh RJ, Moore RA, McQuay HJ. Analysis of individual patient data from clinical trials: epidural morphine for postoperative pain. $\mathrm{Br} J$ Anaesth. 2009;103(6):874-81. https://doi.org/10.1093/bja/aep300.
26. Ventham NT, O'Neill S, Johns N, Brady RR, Fearon KC. Evaluation of novel local anesthetic wound infiltration techniques for postoperative pain following colorectal resection surgery: a meta-analysis. Dis Colon Rectum. 2014;57(2):237-50. https://doi.org/10.1097/DCR.0000000000000006.

27. Hain E, Maggiori L, Prost ADJ, Panis Y. Transversus abdominis plane (TAP) block in laparoscopic colorectal surgery improves postoperative pain management: a meta-analysis. Color Dis. 2018;20(4):279-87. https://doi.org/1 $0.1111 /$ codi.14037.

28. Tran TM, Ivanusic JJ, Hebbard P, Barrington MJ. Determination of spread of injectate after ultrasound-guided transversus abdominis plane block: a cadaveric study. Br J Anaesth. 2009;102(1):123-7. https://doi.org/10.1093/bja/aen344.

29. Stoving K, Rothe C, Rosenstock CV, Aasvang EK, Lundstrom LH, Lange KH. Cutaneous sensory block area, muscle-relaxing effect, and block duration of the Transversus Abdominis plane block: a randomized, blinded, and placebo-controlled study in healthy volunteers. Reg Anesth Pain Med. 2015; 40(4):355-62. https://doi.org/10.1097/AAP.0000000000000252.

30. Aveline C, Le Hetet H, Le Roux A, Vautier P, Cognet F, Vinet E, et al. Comparison between ultrasound-guided transversus abdominis plane and conventional ilioinguinal/iliohypogastric nerve blocks for day-case open inguinal hernia repair. Br J Anaesth. 2011;106(3):380-6. https://doi.org/10.1093/bja/aeq363.

31. Carney J, Finnerty O, Rauf J, Bergin D, Laffey JG, Mc Donnell JG. Studies on the spread of local anaesthetic solution in transversus abdominis plane blocks. Anaesthesia. 2011 ;66(11):1023-30. https://doi.org/10.1111/j.1365-2 044.2011.06855.x

32. Finnerty $\mathrm{O}, \mathrm{McD}$ connell JG. Transversus abdominis plane block. Curr Opin Anaesthesiol. 2012;25(5):610-4. https:/doi.org/10.1097/ACO.0b013e328357b165.

33. Walter CJ, Maxwell-Armstrong C, Pinkney TD, Conaghan PJ, Bedforth N, Gornall $\mathrm{CB}$, et al. A randomised controlled trial of the efficacy of ultrasound-guided transversus abdominis plane (TAP) block in laparoscopic colorectal surgery. Surg Endosc. 2013;27(7):2366-72. https://doi.org/10.1007/s00464-013-2791-0.

34. Latzke D, Marhofer P, Kettner SC, Koppatz K, Turnheim K, Lackner E, et al. Pharmacokinetics of the local anesthetic ropivacaine after transversus abdominis plane block in healthy volunteers. Eur J Clin Pharmacol. 2012; 68(4):419-25. https://doi.org/10.1007/s00228-011-1139-8.

35. Hessian EC, Evans BE, Woods JA, Taylor DJ, Kinkel E, Bjorksten AR. Plasma ropivacaine concentrations during bilateral transversus abdominis plane infusions. Br J Anaesth. 2013;111(3):488-95. https://doi.org/10.1093/bja/aet065.

36. Aniskevich S, Taner CB, Perry DK, Robards CB, Porter SB, Thomas CS, et al. Ultrasound-guided transversus abdominis plane blocks for patients undergoing laparoscopic hand-assisted nephrectomy: a randomized, placebo-controlled trial. Local Reg Anesth. 2014;7:11-6. https://doi.org/1 0.2147/LRA.S61589.

37. Lee TH, Barrington MJ, Tran TM, Wong D, Hebbard PD. Comparison of extent of sensory block following posterior and subcostal approaches to ultrasound-guided transversus abdominis plane block. Anaesth Intensive Care. 2010;38(3):452-60. https://doi.org/10.1177/0310057X1003800307.

38. El-Dawlatly AA, Turkistani A, Kettner SC, Machata AM, Delvi MB, Thallaj A, et al. Ultrasound-guided transversus abdominis plane block: description of a new technique and comparison with conventional systemic analgesia during laparoscopic cholecystectomy. Br J Anaesth. 2009;102(6):763-7. https://doi.org/10.1093/bja/aep067.

39. Niraj G, Searle A, Mathews M, Misra V, Baban M, Kiani S, et al. Analgesic efficacy of ultrasound-guided transversus abdominis plane block in patients undergoing open appendicectomy. Br J Anaesth. 2009;103(4):601-5. https:// doi.org/10.1093/bja/aep175.

40. Huang D, Song L, Li Y, XU Z, Li X, Li C. Posteromedial quadratus lumborum block versus transversus abdominal plane block for postoperative analgesia following laparoscopic colorectal surgery: a randomized controlled trial. J Clin Anesth. 2020:62:109716. https://doi.org/10.1016/j.jclinane.2020.109716.

41. Stannard D, Jang H. Epidural local anesthetics versus opioid-based analgesic regimens for postoperative gastrointestinal paralysis, vomiting, and pain after abdominal surgery. J Perianesth Nurs. 2020;35(3):331-2. https://doi. org/10.1016/j.jopan.2019.07.003.

42. Helander EM, Webb MP, Bias M, Whang EE, Kaye AD, Urman RD. Use of regional anesthesia techniques: analysis of institutional enhanced recovery after surgery protocols for colorectal surgery. J Laparoendosc Adv Surg Tech A. 2017;27(9):898-902. https://doi.org/10.1089/lap.2017.0339.

\section{Publisher's Note}

Springer Nature remains neutral with regard to jurisdictional claims in published maps and institutional affiliations. 